\title{
PhD Student Ambassadors: Partners in Promoting Graduate Research
}

\author{
Liesel Mitchell ${ }^{1^{*}}$, Shabnam Seyedmedhi ${ }^{2^{*}}$, and Rachel Spronken-Smith ${ }^{3^{*}}$ \\ University of Otago, Dunedin, New Zealand \\ ${ }^{1}$ PhD candidate, National Centre for Peace and Conflict Studies \\ ${ }^{2} \mathrm{PhD}$ candidate, Department of Marketing \\ ${ }^{3}$ Dean, Graduate Research School \\ *Denotes equal authorship \\ Contact: rachel.spronken-smith@otago.ac.nz
}

\section{ABSTRACT}

The aims of this research were to explore the experiences of staff and postgraduate students in an ambassador scheme, develop a model of partnering with postgraduate students in the administrative space, and consider implications for partnership initiatives. A qualitative case study was undertaken of a "Graduate Research Ambassador Scheme", involving a dean employing two PhD students as paid ambassadors to help promote a vibrant graduate research culture. Research diaries were kept by each partner, regular research discussions occurred, and each partner wrote a reflective account of their experiences. These data were collaboratively analysed using a general inductive approach. All partners had very positive experiences, but there was some uncertainty regarding the nature of the role and some institutional challenges. A model of staff-student partnership within the administrative space was developed that included three main influences on effective partnerships: roles in partnership, structural characteristics, and personal characteristics. The model highlights the need for clear articulation of roles and tasks, the challenge of institutional cultures, and the way that resources, time, and space can either hinder or help partnerships. Personal characteristics such as trust, respect, and informal communication can significantly mitigate challenges and build fruitful partnerships.

\section{KEYWORDS}

student partners; administration; graduate research; PhD students 


\section{INTRODUCTION}

"Partnership is essentially a process of engagement, not a product" (Healey, Flint \& Harrington 2014, p. 7).

In recent years, scholars have taken an interest in promoting students as partners in higher education. The partnership engagement between students and staff (faculty, administrators, and managers) in higher education can occur in a range of areas such as teaching and learning, research, governance, quality assurance, community engagement, and also in extra-curricular activities (Healey, Flint, \& Harrington, 2016, p. 2). Such partnership can result in a wide range of positive outcomes for students including increased engagement, motivation and ownership for learning, increased self-confidence, better understanding of "other's" experiences, enhanced relationships with staff, and raised awareness of employability skills (Mercer-Mapstone et al., 2017, p. 11). Positive outcomes also occur for staff such as enhanced relationships with students, improved teaching and curriculum materials, greater teaching enjoyment, and increased understanding of student experiences (Mercer-Mapstone et al., 2017, p. 12).

Partnerships between students and staff should be engaging, with a particular focus on how to facilitate "high levels of active student participation" (Healey et al., 2016, p. 2). To achieve a true partnership, students should have a significant amount of autonomy, independence, and choice (Bovill, Cook-Sather, \& Felten, 2011; Healey et al., 2014). Moreover, the partnership should be at a level higher than merely consultation and involvement in decision-making (Williamson, 2013). Partnership may be promoted by honesty, trust, courage, and responsibility, and factors such as empowerment, authenticity, inclusivity, reciprocity, and plurality (Healey et al., 2016, p. 6). Partnership requires a "shared vision and values, sharing of knowledge, regular communication between partners; and joint decision-making and accountability" (Healey et al., 2014, p. 26). Alongside these core values, Bovill and Felten (2016) advocate that since partnership may be a new territory for students, staff, and institutions, partnership practices in higher education need to be investigated and theorised.

A recent model of students as partners (Healey et al., 2016) includes four main areas of partnering: learning, teaching, and assessment; curriculum design and pedagogic consultancy; scholarship of teaching and learning; and subject-based research and inquiry. The model is centred on partnership learning communities. This model focuses mainly on disciplinary learning spaces, although Healey et al. (2016) do provide examples of partnerships beyond the curriculum. We use the term "administrative space" to refer to departments, offices, or units that sit outside the main academic faculties but whose function is to support teaching and learning in the institution. In our case study, "administrative space" refers specifically to a graduate research school. Students as partners in administrative spaces may also encompass an employer-employee relationship similar to other student administrative roles such as exam marking, library administration, and other office work. However, partnership means something different from only having an employer-employee relationship. In our case study, the partnership was between a dean and two PhD students, who were employed as ambassadors. We suggest that the particular role of "ambassador," which is broad in its job description, helped to facilitate the partnership engagement between staff and students in this administrative space.

Some research has been conducted on students as partners in the administrative space where the intent is to improve teaching and learning. Mercer-Mapstone et al. (2017) 
reported that of the 65 articles they analysed in a systematic review on students as partners, $40 \%$ occurred outside of a discipline. Of all partnerships studied, $54 \%$ were categorised into Healey et al.'s (2014) "curriculum design and pedagogic consultancy," with $31 \%$ in "SoTL," and 22\% in "learning, teaching and assessment" (Mercer-Mapstone et al., 2017, p.7). Some of these partnerships involved students partnering in administering teaching conferences or symposia. For example, Peseta et al. (2016) described an undergraduate student ambassador scheme at the University of Sydney in which seven students at undergraduate level assisted in promoting a Sydney Teaching Colloquium. Also, research has occurred on student-led conference initiatives within coursework, such as an event management course (Lawrence \& McCabe, 2001; Moscardo \& Norris, 2004), and computer science course (Gruba \& Sondergaard, 2000), as well as student-led extracurricular conference initiatives (e. g., Ramdayal, Stobbe, Mishra, \& Michaut, 2014). These examples mainly involved partnerships that occurred with undergraduate students. Mercer-Mapstone et al. (2017) noted that only $20 \%$ of the articles analysed reported on partnerships with postgraduate students and only $35 \%$ involved paid work.

In this article, we report on a partnership scheme involving postgraduate students as paid ambassadors working in the administrative space alongside the dean of a graduate research school. We define the role of student ambassador as: postgraduate students employed to help promote, implement, and evaluate activities to support the graduate research culture.

The aims of the article are to:

- explore the experiences of the ambassadors and the dean in participating in the Graduate Research Ambassador Scheme;

- develop a model of partnering with postgraduate students in the administrative space; and

- consider implications for future partnership initiatives.

In the following, we will first provide some background on the ambassador scheme and then move on to describe the research methods.

\section{The Graduate Research Ambassador Scheme}

The University of Otago is a research-intensive university, based in Dunedin, New Zealand. The University has about 22,000 students including over 2000 doctoral and master's research students. The Dean of the Graduate Research School (GRS), Rachel Spronken-Smith (third author, hereafter referred to as Rachel ${ }^{\mathrm{D}}$, where ${ }^{\mathrm{D}}$ signals the dean), initiated the Graduate Research Ambassador Scheme as a way to critique and refresh how the School promoted a vibrant graduate research culture, and therefore enhance the learning environment for postgraduate students. In April 2016 she advertised for ambassadors (about 100 hours work each) and recruited two: the first two authors, Liesel Mitchell (Liesel ${ }^{\mathrm{A}}$ ) and Shabnam Seyedmehdi (Shabnam ${ }^{\mathrm{A}}$ ) (note ${ }^{\mathrm{A}}$ signals the ambassadors). While the ambassador positions were paid roles, they were created with a partnership model in mind-there were no pre-set tasks determined by the dean, the nature of role was to be negotiated with the students, and because the ambassador role was brand new, there was scope for active student participation in developing and shaping the role. Although some employee/student relationships may be similar, we argue that the particular role of ambassador generated a unique partnership, and in this case, one that focused on enhancing the learning environment for postgraduate students. 
Office space was unavailable in the School, so the ambassadors continued to use their own offices, gathering in the School for fortnightly meetings. In the early meetings, we discussed ways to support and promote the graduate research culture and a few activities were agreed upon, as well as a commitment made to research the scheme. The ambassadors decided to profile current graduate research students and to develop and implement a new event to showcase graduate research. Accordingly, Liesel ${ }^{\mathrm{A}}$ and Shabnam ${ }^{\mathrm{A}}$ began meeting with postgraduate student representatives across the University and profiling students. However, in June, it was collectively agreed to develop a novel "Dance Your Thesis" event for the first time at Otago. For the next three months, the ambassadors focused on organising and advertising, gaining sponsorship, sorting criteria for entries, and finding judges. The event was run in September 2016, and the entrants appreciated the creative outlet for presenting their research. The final phase of the scheme involved researching the initiative, with our analysis presented here.

\section{METHODOLOGY}

We used a qualitative case study research approach for addressing our research aims. The case study was the Graduate Research Ambassador Scheme described above. Over the course of the partnership, we (Liesel ${ }^{A}$, Shabnam ${ }^{A}$, and Rachel ${ }^{D}$ ) developed a collaborative model of research and practice, which involved collective and individual tasks, collaborative and self-directed reflection, and critical analysis of how student-staff partnership operated in practice. Over an eight-month period, we kept research diaries and meeting notes, and had many discussions about our research. We then collectively generated a set of questions to guide further examination of the partnership. The questions included probes regarding: the expectations and roles of the ambassador; defining, experiencing, and qualifying partnership; and advice and ideas for future partnership projects. We all responded to the questions, shared our narratives, and then discussed and analysed the narratives over a series of team meetings.

We used a general inductive approach (Thomas, 2006) to analyse our data, which involved identifying themes in relation to our research aims, as well as allowing themes to emerge in a grounded approach. Our thematic analysis was guided by Bronstein's (2003) model for effective interdisciplinary collaboration. Bronstein's model has an interdisciplinary and collaborative focus, which complements our interest in developing effective administrative partnerships. All three partners have different disciplinary backgrounds (Peace and Conflict Studies, Marketing, and Geography and Higher Education), and like Bronstein (2003), we wanted to achieve goals that required cooperation and could not be attained when working by ourselves (p. 299). While partnership is always collaborative work, collaborative work is not always a partnership. For example, a staff-student collaboration on an academic paper may, but will not always, facilitate active student participation or encourage co-decision making in the process of collaboration. The Bronstein (2003) model was developed from an interdisciplinary search of theory and relevant research in the social work field, and it includes core elements of interdependence, newly created professional activities, flexibility, collective ownership of goals, and reflection on the process (Figure 1). These core elements are influenced by four categories: professional roles, structural characteristics, history of collaboration, and personal characteristics. Our narrative analysis was guided by these four categories. However, it soon became apparent 
that the "history of collaboration," was not relevant to our case because students may have little background in the type of collaborative initiatives that cater for a particular profession in Bronstein's (2013) model. Furthermore, we also adapted "professional roles" into "roles in partnership," since this better reflected the nature of these roles in our context. Consequently, our thematic analysis focused on: roles in partnership, structural characteristics, and personal characteristics.
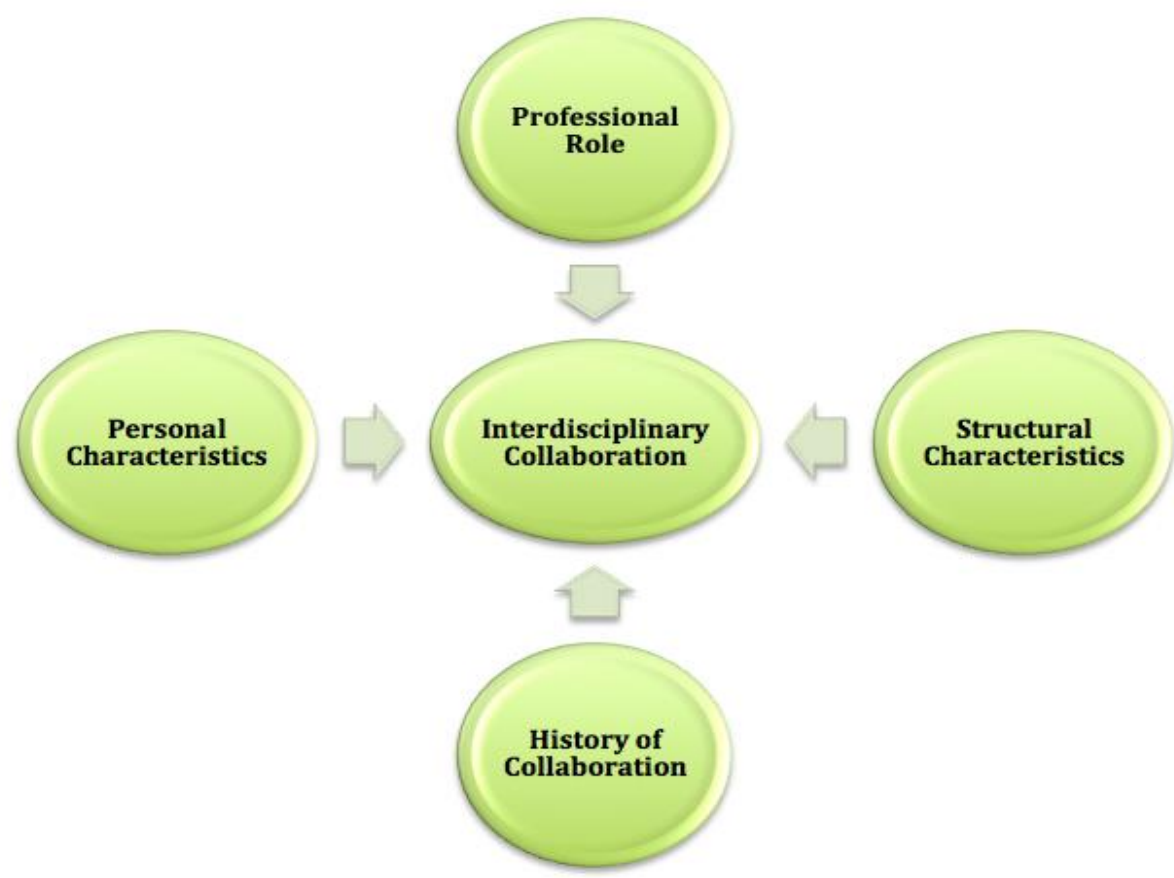

Figure 1. Model for effective interdisciplinary collaboration (adapted from Bronstein, 2003, p. 303).

Each co-author read the narratives to extract key themes relating to one of the categories, and then we collectively considered and critiqued the thematic analysis until we were in agreement on key findings. In the following sections we have constructed responses to the three areas of partnership using direct quotes from our research diaries and from our narratives. We acknowledge that our data are our own subjective ideas, which have in turn been used to support the construction of a partnership model. When research is conducted in such a subjective way, it is vital that we incorporate mechanisms to facilitate both critical and reflective practice. Our methodology uses credibility, transferability, and confirmability checks to maintain our research transparency and trustworthiness (Guba \& Lincoln, 1989). For example, in terms of credibility, we observed and analysed the partnership over a long time period (eight months), and used peer debriefing. For transferability, the analysis of our experiences allowed for a thick description of the partnership. For confirmability, we used reflexivity and triangulation of partnership experiences. 


\section{RESULTS}

In this section we present our findings, drawing on Bronstein's (2003) model to discuss the major influences on partnership in the administrative space: roles in partnership, structural characteristics, and personal characteristics.

\section{Roles in partnership}

Bronstein (2003) defines professional roles as: upholding the ethical character of your profession; an "allegiance to the agency setting" and to the profession; "respect for professional colleagues;" a "holistic view of practice" in keeping with the profession; and "a perspective that is similar or complementary to collaborators' perspectives" (p. 302). In our case, we are dealing with graduate research culture rather than a profession, nonetheless, the fundamental elements of Bronstein's model remain relevant.

During the ambassador recruitment, Rachel ${ }^{\mathrm{D}}$ looked for students who "displayed ambassadorial qualities such as being good role models ... enthusiastic and passionate about graduate research." She was hoping that the ambassadors could work in a collaborative way with her so she could "draw on their experience grounded as participants in graduate research to see what might be of interest to the community" (Rachel ${ }^{\mathrm{D}}$ ). Therefore, Rachel ${ }^{\mathrm{D}}$ wanted to collaborate with students who possessed similar values for and an allegiance to graduate research, as well as who brought in a different perspective. Such aspects are well aligned with Bronstein's professional roles, and in our case, also with "roles in partnership" within the higher education setting.

There were some problematic aspects of roles in partnership including the notion of ambassadorship and an uncertainty over what that position would entail. Although the role contained elements similar to the more familiar "student representative" role, in terms of gaining views from the wider postgraduate student body, the positions were more about marketing graduate research and involved project work to enhance the learning environment. The branding of the position as an ambassador was attractive to the students, evoking a sense of prestige and importance: "The advertisement looked very attractive to me as first it had an amazing title 'ambassador' and it was prestigious too as it was something related to GRS!" (Shabnam ${ }^{A}$ ). There was also a sense the University community would listen to people who were ambassadors for the Graduate Research School and who could make changes. Shabnam ${ }^{A}$ thought that such a reputation "was very helpful for us when we contacted other people and we introduced ourselves as GRS Ambassadors, they got back to us in a way that showed they really counted on us as a GRS person!" The notion of ambassadorship also evoked connections - as Shabnam ${ }^{A}$ said, it created "a bridge between two groups of stakeholders." There was a sense of responsibility to the stakeholders to "take the insights and ideas from both parties [students and staff] in order to plan and implement things" (Shabnam $\left.{ }^{\mathrm{A}}\right)$. Liesel ${ }^{\mathrm{A}}$ "assumed that the position would require interaction with lots of different people, to feel comfortable talking in various environments and to have a certain confidence to carry off the role of 'ambassador'."

While the two students had a perception of what an ambassador role entailed, there was also some uncertainty because it was a new initiative. Liesel ${ }^{A}$ wondered if she "didn't quite fulfil some of the necessary criteria to own such a title-as in, I am not sure the role was given the profile that it needed in order to be called an ambassador, or if it was just a title that wasn't very easy/familiar to students and staff in the university, therefore people were not sure exactly who/what you were." In this case, her unease was not about her 
ability to take on the role but more about whether the role would be understood in the university community. There was also uncertainty about who the ambassadors were representing. Rachel $I^{D}$ thought the ambassadors would represent graduate research, while Shabnam ${ }^{A}$ thought she was representing the Graduate Research School. Liesel ${ }^{A}$ said, "I never quite worked out who we, as 'the ambassadors', were representing." Lack of clarity meant the position and title of "ambassador" were difficult to understand.

Despite these uncertainties, there was a shared understanding, particularly around key tasks. Liesel ${ }^{\mathrm{A}}$ confirmed, "Shabnam and I had been hired to promote the events and culture of the GRS/postgrad students." Shabnam ${ }^{A}$ noted: "this position required coordination for planning and hosting events." Liesel ${ }^{A}$ also described it as "administrative work-meetings, emails, communicating with student representatives in the University." Rachel ${ }^{\mathrm{D}}$ had deliberately hired Liesel ${ }^{\mathrm{A}}$ and Shabnam ${ }^{\mathrm{A}}$ for their "potential fit to a team, their ideas for enhancing the graduate research community at Otago, and their experience in the use of social media." She wanted ambassadorial and teamwork qualities, but she also recruited for diversity, deliberately choosing both a domestic student (Liese $\left.{ }^{A}\right)$ and an international student (Shabnam ${ }^{\mathrm{A}}$ ).

\section{Structural characteristics}

Structural characteristics refer to the structures that exist around and within the collaborative partnership relationship. For example, the existing hierarchical structures of the university shape certain aspects of the staff-student partnership. Bronstein (2003) notes relevant structural characteristics include "an agency culture that supports interdisciplinary collaboration, administrative support, professional autonomy, and the time and space for collaboration to occur" p. 303). Additionally, structural characteristics can act as a conduit or a barrier to staff-student partnership, depending on factors such as the "ways that an organisation and supervisor allocate resources and assign work" (Bronstein 2003, p. 303). Therefore, structures such as those of authority, the type of collaborative institutional culture the partnership exists in, the access to and/or limitations on resources, and the way time and space is used, can be significant factors that influence the student-staff partnership. These structural characteristics were present in our reflections and are examined in this section.

Structural characteristics cannot be completely divorced from the existing collaborative culture of the institution, which in this case, is the University of Otago Graduate Research School. Staff and student roles carry existing hierarchies, pre-conceived roles of teacher and student, and the associated power dynamics that can all influence student-staff partnerships. Tertiary institutions tend to maintain distinct categories of staff and student, making it challenging to ignore existing structures to build interdependence and trust within these settings. Some of these challenges were highlighted by Shabnam ${ }^{A}$ who said, "I think it would be great if we as ambassadors were introduced better to university and postgrads." Liesel ${ }^{\mathrm{A}}$ commented, "we needed Rachel to sign off on various things and approval around certain University regulations, yet it was sometimes difficult for us to know what we needed to initiate, and what we needed to get approval for." Rachel ${ }^{\mathrm{D}}$ was also aware of these power dynamics: "I say 'equal' in inverted commas as clearly there was always going to be an element of unequal power dynamics at play given our respective roles. Nevertheless, I hoped that both ambassadors would feel it was a safe environment to volunteer ideas and that their voices would be listened to and acted upon." 
Access to resources can help or hinder the partnership collaboration. Both ambassadors were paid, indicating that the work being done was valued. However, continuation of the ambassador scheme relied on institutional funding, as noted by Rachel ${ }^{\mathrm{D}}$, "I would love to be able to continue with the Graduate Research Ambassadors, but this, of course, is dependent on funding. In my role as Dean, I get a research support fund, and I used part of this fund to employ the two ambassadors." Thus in some cases students may not be paid, which can hinder the development of activities together, while also affecting interdependence and collaboration.

The ambassadors were given the freedom to create an ambassador t-shirt and were given access to honorary staff ID cards. These two acts symbolised what Bronstein (2003) refers to as "newly created professional activities" (p. 300). Shabnam A said what she really liked "was getting an honorary staff card which distinguishes us from other students and gives us identity as ambassadors as the staff of the university." Rachel ${ }^{D}$ reported "they [the ambassadors] requested access to staff cards and a Graduate Ambassador T-shirt, both of which I supported as they were ways to both legitimise and advertise their work." T-shirts and staff ID cards helped acknowledge the unique role of the ambassadors and legitimised the job, both within the partnership and in the eyes of other staff and students.

Although access to resources helped to mitigate some hierarchical structural characteristics, the limitations placed on other resources had the opposite effect. Some of the existing administrative structures meant that key responsibilities of the ambassador role, such as utilising social media, were not possible. This was a frustration noted by the ambassadors: "when we were trying to negotiate ways that we could communicate not only the work of the ambassadors, but also promote the events we were wanting to develop, and information about the work of GRS, we were unable to get access (as administrators) to the Facebook page" (Liesel $\left.{ }^{A}\right)$. Shabnam ${ }^{A}$ agreed access "would have helped us to promote the events much better." Denial of access to resources reinforced the hierarchical divide between staff and students, and it inadvertently limited certain potential for the students to feel "true partners."

Time was a structural characteristic of the partnership that was always evident as all three partners were juggling different schedules with different pressures. However, that said, Rachel ${ }^{\mathrm{D}}$ made every effort to be flexible in order to give as much room to accommodate our collaborative work. Rachel ${ }^{\mathrm{D}}$ said "they [the ambassadors] were honest about workloads and we renegotiated tasks to fit around their commitments." While there was always a relaxed feeling to meetings, all partners took their professional role seriously, which was demonstrated by how time was used efficiently for meetings and assigning tasks. For example, Shabnam ${ }^{A}$ said, "we both act very professionally and usually our meetings are about 30 to 45 minutes but we are very productive. We decide about everything and divide the tasks properly."

Finally, space was a structure reflected in the default location of our regular meetings taking place in Rachel ${ }^{\mathrm{D}}$ 's office in the Graduate Research School. Although this was not an overt decision, it inadvertently strengthened traditional roles of student and staff instead of building up the partnership roles. Liesel ${ }^{\mathrm{A}}$ noted, "perhaps the space where we met-mixing it up from meeting only in Rachel's office-and taking some of our meetings outside of the University, and even organising to meet up in a purely social capacity, would have also helped to create different understanding of our roles." Moreover, if the ambassadors had an office space or had been incorporated into the Graduate Research 
School generally, there may have been less structural power dynamics from the deeper institutional culture, regardless of other collaborative elements, that were part of the partners' meeting space. Rachel ${ }^{\mathrm{D}}$ acknowledged, "One aspect I did not manage well was integrating the ambassadors into the Graduate Research School," and this factor was reiterated by LieselA: "It was interesting being a part of the GRS, yet because other staff members were not entirely sure who we were or what we did, I never quite felt a part of the wider department, although there were efforts to include us."

\section{Personal characteristics}

Personal characteristics can help build rapport among the partners in a successful partnership. As Bronstein (2003) explains, personal characteristics include "the way collaborators [partners] view each other as people, outside of their professional role" (p. 304). These kinds of characteristics foster the relationships within a partnership and were evident in our reflections (as we outline below).

Personal characteristics contribute to the emotional bond between partners and make the collaborative experience much more enjoyable. Informal communication and informal relationships play an important role in this partnership and help foster collegial working relationships. Here, informal communication at the beginning of the fortnightly meetings was noted as being an enjoyable aspect of meeting for the three partners. Rachel ${ }^{\mathrm{D}}$ said "the fortnightly meetings, despite being late on Friday afternoons, were a highlight of my week. I looked forward to seeing both ambassadors as they were always enthusiastic about the meetings, and there was an easy collegial working relationship." These conversations were equally enjoyable for the ambassadors. Shabnam ${ }^{A}$ said she "enjoyed our regular meetings as they were friendly ... we started with chitchatting." Liesel ${ }^{\mathrm{A}}$ also pointed out "the non-work conversation in our meetings helped to establish more of a collaborative connection between three of us." Furthermore, Liesel ${ }^{\mathrm{A}}$ believed that the friendly conversations "helped to shape our relationship beyond the staff-student relationship." A further example of this informal aspect of the partner relationship was socialising outside of work: "Another positive experience for me was being invited to the dean's house for a potluck where I had the opportunity to meet other GRS people and feeling belonging and being a part of the team" (Shabnam $\left.{ }^{A}\right)$. In order to enhance the partnership experience, then, informal communication and informal relationships play an important role in easing the formal aspects of the partnership, make it enjoyable, and foster the feeling of being in a team.

Other personal characteristics such as trust and respect were mentioned frequently in our reflections. Shabnam ${ }^{A}$ commented, "the relationship between us is very respectful and friendly," and Liesel ${ }^{\mathrm{A}}$ said, "[at] our meetings I always felt respected, welcomed, and appreciated." Due to the fact that a successful partnership is built on a foundation of trust, the mutual trust referred to by the ambassadors may help foster the collaborative environment and encourage all partners to be active members. As well, "understanding" was evident in our reflections as another characteristic being necessary for an effective partnership. Shabnam ${ }^{A}$ thought the other two partners were very friendly and understanding, evidenced by their flexible response when she had to travel to her sister's wedding earlier than the expiry date of the work contract. As a result, she said this made her more committed to the team as she tried to compensate while she was away.

In summary, the personal characteristics of trust, respect, and understanding 
allowed the partners to actively foster good relationships as they could comfortably express their work ideas, while also enjoying each other's company. The informal opportunities for communication and relationship building seemed to be a critical element in developing collaborative staff-student relationships.

\section{DISCUSSION}

In this section, we use our findings to develop a model for staff-student partnerships in the administrative space, and then we consider the implications of our research. Finally, we discuss the limitations of our study.

\section{A model for partnering with students in the administrative space}

Analysis of our experiences in the Graduate Research Ambassador Scheme led to the development of a model of partnership with postgraduate students in the administrative space (Figure 2). Our research was informed by Bronstein's (2003) model for interdisciplinary collaboration and like Bronstein, we found that roles, structural characteristics, and personal characteristics were key influences on collaboration or partnership. However, as noted earlier, Bronstein's "history of collaboration" was not pertinent for our student-staff partnership model. Therefore, we focus on three main influences for effective partnering: roles in partnership, personal characteristics, and structural characteristics.

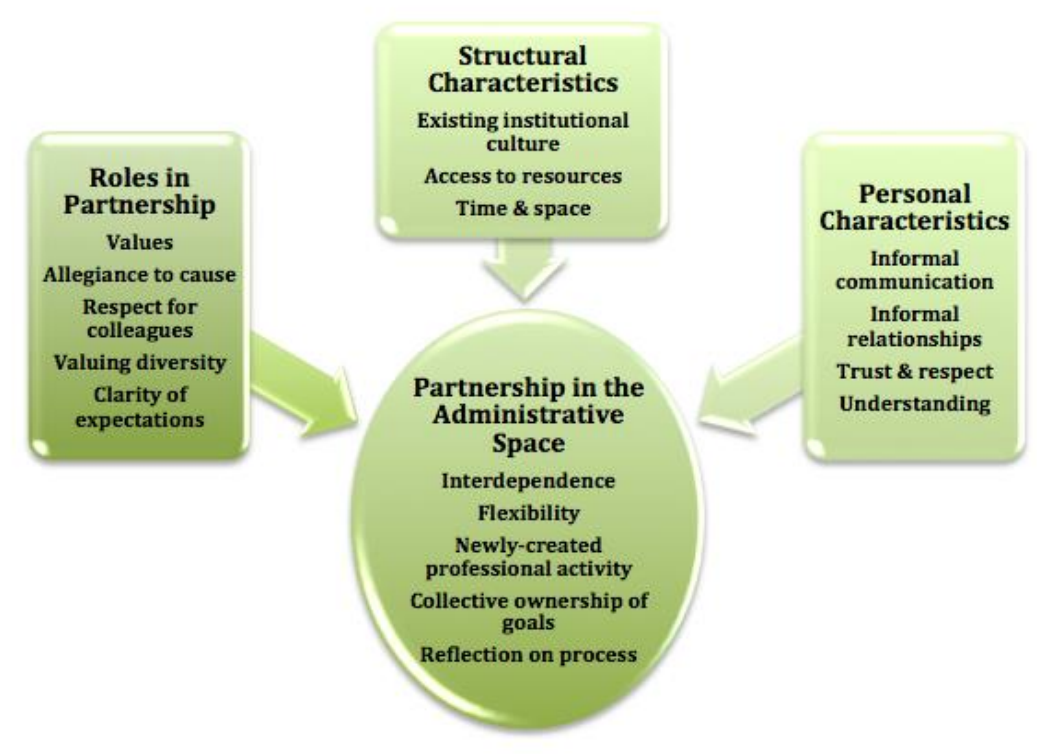

Figure 2. Model of effective partnering with students in the administrative space (adapted from Bronstein's (2003) model, "Influences on Interdisciplinary Collaboration", p. 304). 
Roles in partnership includes values, allegiance to cause, respect for colleagues, valuing diversity, and clarity of expectations. It was apparent that all three partners placed value on the importance of graduate research and shared a strong allegiance to the cause of promoting a vibrant graduate research culture at the University. Having a shared vision and values were noted by Healey et al. (2014) as being essential for a true partnership. For an effective partnership, it is also essential that the partners value diversity. Analysis of the partner narratives clearly demonstrated this element. In the ambassador recruitment process, Rachel ${ }^{\mathrm{D}}$ deliberately selected for diversity by choosing a domestic student and an international student, and all partners had different disciplinary backgrounds (Peace and Conflict Studies, Marketing, and Geography and Higher Education). Shabnam ${ }^{\mathrm{A}}$, an Iranian, was well networked with international postgraduates and always offered valuable insight into some of the needs and expectations from this group. Liesel ${ }^{\mathrm{A}}$, a New Zealander, was also widely networked with both domestic and international students and importantly had some very strong community links, which proved valuable for sponsorship. Bovill (2017) noted the need for inclusivity in student partnerships and for such partnerships to include harder-to reach or previously excluded students (p. 1).

The only aspect of roles in partnership that was less well achieved was clarity over expectations. The "ambassador" title, while appealing to the students, created uncertainty regarding expectations around roles, and these uncertainties were not well clarified. Peseta et al.'s (2016) student ambassador initiative did not report any specific difficulties in relation to the title, but perhaps this was because the students were very clear about their roles. The importance of clear expectations has also been noted by Marquis et al. (2016). Yet, as we suggested earlier, the ambiguity of the ambassador title may have provided wider parameters for staff and students to engage effectively as both positions co-designed and co-developed the role in partnership.

Personal characteristics, such as informal communication, informal relationships, trust, respect, and understanding, all helped to generate an effective partnership (Figure 2). These characteristics contributed to building up rapport and forming a sense of belonging to the team, thus playing an important role in enhancing the interpersonal relationships among the partners. Mutual trust and respect are required for effective communication and honest dialogue within a partnership. By cultivating and maintaining trust through actions and words, partners may be more likely to share their ideas and take initiative. The importance of personal characteristics in partnerships has also been noted by Cook-Sather, Bovill, and Felten (2014) and Healey et al. (2014).

Figure 2 also highlights how structural characteristics are an essential element to consider in student-staff partnership in the administrative space. Our findings argue that existing institutional culture including hierarchy, access to resources, time, and space, can support or hinder the partnership, or what Marquis et al. (2016) refer to as a collaboration that can be "simultaneously beneficial and challenging" (p. 5). Peseta et al. (2006) found that their student ambassadors were disappointed by institutional practices and norms that hindered their work to enhance the learning environment. Mercer-Mapstone et al. (2017) reported heightening power inequalities as a negative outcome of partnerships with students. To try and overcome aspects of institutional hierarchy, we used the ambassador role to distribute power more equally, and we accepted the ambassadors as honorary staff. 
That said, all three partners commented on aspects of the structural culture of the institution that made true partnership challenging, particularly in the administrative space where certain information and systems were not accessible.

Time was a factor beyond our control that seemed to impact equally on all three partners. Marquis et al. (2016) and Bovill (2017) have both noted that time is one of the key challenges faced by partnerships due to the difficulty of creating meaningful relationships that embody characteristics such as trust and respect within tight time frames. However, professional roles were taken seriously, and there was a shared understanding of efficient use of time, regardless of other commitments all partners were juggling. One way that time was acknowledged, was paying the ambassadors by the hour, so all student work could be valued. Promoting work-based paid partnerships has been advocated as a way to sustain staff student partnerships (Curran \& Millard, 2016).

Physical space was a structural characteristic that we could have used differently to better facilitate staff-student partnership. The importance of physical space has received less attention in the literature, yet in our case, having office space within the School would have mitigated some structural barriers, as well as foster a stronger sense of belonging to the School. Additionally, for us, many of the structural obstacles were managed by the way the personal characteristics were valued, both formally and informally. Respectful communication enabled us to either bridge hierarchical structures, or acknowledge the structures to negotiate resources, and manage time and space constraints.

Central to our model is the partnership of staff and students in the administrative space (Figure 2). We found Bronstein's (2003) core elements for effective collaboration were applicable in our model: interdependence, newly created professional activities, flexibility, collective ownership of goals, and reflection on process. We each noted how partnership is rewarding, and creative, with the added benefit of a sense of shared learning irrespective of our roles. We also found that partnering with students in the administrative space was characterised by very positive emotions. Felten (2017) suggested that not enough attention is paid to the emotional aspect of partnerships. Importantly, we found that some of the challenges faced by student-staff partnership, particularly structural elements, were able to be successfully managed by aspects of the "personal characteristics" element of our model. In other words, relationship building is key to fruitful partnership. This echoes Healey et al. (2014) identifying how partnerships are "encouraged by structures . . . that support partnership, shared values, and attitudes and behaviours that each member . . . signs up to and embodies in practice" (Healey et al., 2014, p. 28). These factors may not be unique in administrative partnerships, but they may be enhanced by the role of ambassador, and perhaps be a benefit particular to staff-student collaboration within this context.

\section{Implications for partnering with students in the administrative space}

The main implication emerging from our research relates to the tension between clear expectations regarding job descriptions, roles, and tasks, and maintaining some flexibility of terms, such as our use of "ambassador," in creating effective partnerships. Our research also highlights the importance of integrating students with other administrative staff to give the students a sense of belonging to the structures and roles that are already in existence. Providing office space for student partners, allowing access to key administrative tools such as social media, and involving them in social functions, are ways that may mitigate these gaps. Finally, it is important to allow the space and time for informal 
communication to enable relationships to be built.

\section{Limitations of the study}

The major limitation of this study is that the model of partnering with students has been generated from only one case study. Also, the analysis was undertaken by the partners, who have a particular perspective and therefore the findings will reflect their views. Despite this, we believe our model and the findings will be transferable and useful to partnerships in other university contexts.

\section{CONCLUSION}

In this article, we aimed to explore the experiences of partners in a Graduate Research Ambassador Scheme, develop a model of partnering with postgraduate students in the administrative space, and consider implications for future partnership initiatives. Using a reflexive and collaborative approach, compiling our personal experiences of partnership, we adapted Bronstein's (2003) model of interdisciplinary collaboration to provide a theoretical framework for our analysis. Central to the model were elements such as interdependence, newly-created professional activities, collective ownership of goals, and reflection on process. Similar to previous research, partnering with students evoked very positive emotions, but there were some institutional challenges. The key influences on effective partnering included the need for clear articulation of roles and tasks, and the capacity to deal with challenging institutional cultures. In addition, we identified that the broad parameters of an "ambassador" role in the administrative space helped provide a positive structure for partnership. Resources, time, and space can either hinder or help partnerships, and key personal characteristics such as trust, respect, and understanding, as well as informal communication and relationships can help to build and cement partnerships. Further studies need to be carried out in order to test the model and to determine the model's applicability in other contexts.

\section{NOTE ON CONTRIBUTORS}

Liesel Mitchell is a PhD student with the National Centre for Peace and Conflict Studies, and employed as a Graduate Ambassador at the University of Otago. Liesel currently researches participation in nonviolent civil resistance, and has broader interests in education, conflict resolution, restorative justice and ways to use online learning.

Shabnam Seyedmehdi is a PhD student in the Marketing Department at the University of Otago. Her research interests lie in multidisciplinary areas such as tourism marketing, branding and non-profit organisations. Prior to academia, she has had practical business experience in Malaysia.

Rachel Spronken-Smith is a professor in higher education and geography. She is currently Dean of the Graduate Research School at the University of Otago. Rachel continues to teach and research, with her interests in higher education including inquiry-based learning, graduate outcomes and doctoral education. 


\section{REFERENCES}

Bovill, C. (2017). A framework to explore roles within student-staff partnerships in higher education: Which students are partners, when, and in what ways? International Journal for Students as Partners, 1(1).

Bovill, C., \& Felten, P. (2016). Cultivating student-staff partnerships through research and practice. International Journal for Academic Development, 21(1), 1-3.

Bovill, C., Cook-Sather, A., \& Felten, P. (2011). Students as co-creators of teaching approaches, course design, and curricula: Implications for academic developers. International Journal for Academic Development, 16(2), 133-145.

Bronstein, L. R. (2003). A model for interdisciplinary collaboration. Social Work, 48(3), 297306.

Cook-Sather, A., Bovill, C., \& Felten, P. (2014). Engaging students as partners in learning and teaching: A guide for faculty. San-Francisco: John Wiley \& Sons.

Curran, R., \& Millard, L. (2016). A partnership approach to developing student capacity to engage and staff capacity to be engaging: Opportunities for academic developers. International Journal for Academic Development, 21(1), 67-78.

Felten, P. (2017). Emotion and partnerships. International Journal for Students as Partners, 1(2).

Gruba, P., \& Sondergaard, H. (2000, Jan 31-Feb 3). Transforming communication skills instruction: The conference approach. Paper presented at Computer Science Conference: ACSC 2000, Australasia, Canberra, Australia. doi: 10.1109/ACSC. 2000.824385

Guba, E. G., \& Lincoln, Y. S. (1989). Fourth generation evaluation. Newbury Park, CA: Sage Publications.

Healey, M., Flint, A., \& Harrington, K. (2014). Engagement through partnership: Students as partners in learning and teaching in higher education. York: The Higher Education Academy. Retrieved from https://www.heacademy.ac.uk/engagement-throughpartnership-students-partners-learning-and-teaching-higher-education

Healey, M., Flint, A., \& Harrington, K. (2016). Students as partners: Reflections on a conceptual model. Teaching \& Learning Inquiry, 4(2), 1-13.

Lawrence, M., \& McCabe, V. (2001). Managing conferences in regional areas: A practical evaluation in conference management. International Journal of Contemporary Hospitality Management, 13(4), 204-207.

Marquis, E., Puri, V., Wan, S., Ahmad, A., Goff, L., Knorr, K., Vassileva, I., \& Woo, J. (2016). Navigating the threshold of student-staff partnerships: A case study from an Ontario teaching and learning institute. International Journal for Academic Development, 21(1), 4-15.

Mercer-Mapstone, L., Dvorakova, S. L., Matthews, K. E., Abbot, S., Cheng, B., Felten, P., . . . Swaim, K. (2017). A systematic literature review of students as partners in higher education. International Journal for Students as Partners, 1(1).

Moscardo, G., \& Norris, A. (2004). Bridging the academic practitioner gap in conference and events management: Running events with students. Journal of Convention and Event Tourism, 6(3), 47-62.

Peseta, T., Bell, A., Clifford, A., English, A., Janarthana, J., Jones, C., . . \& Z Zhang, J. (2016). Students as ambassadors and researchers of assessment renewal: Puzzling over the 
practices of university and academic life. International Journal for Academic Development, 21(1), 54-66.

Ramdayal, K., Stobbe, M. D., Mishra, T., \& Michaut, M. (2014). Building the future of bioinformatics through student-facilitated conferencing. PLoS Computational Biology, 10(1).

Thomas, D. R. (2006). A general inductive approach for analyzing qualitative data. American Journal of Evaluation, 27(2), 237- 246.

Williamson, M. (2013) Guidance on the development and implementation of a Student Partnership Agreement in universities. Edinburgh: Sparqs. Retrieved from http://www.sparqs.ac.uk/upfiles/Student\%20Partnership\%20Agreement\%20Guidance \%20-\%20final\%20version.pdf 